NBER WORKING PAPER SERIES

\title{
THE CONSEQUENCES OF RIGID WAGES IN SEARCH MODELS
}

\author{
Robert Shimer \\ Working Paper 10326 \\ http://www.nber.org/papers/w10326 \\ NATIONAL BUREAU OF ECONOMIC RESEARCH \\ 1050 Massachusetts Avenue \\ Cambridge, MA 02138 \\ February 2004
}

This paper was originally titled "The Cyclical Behavior of Labor Markets". I thank seminar audiences at the European Economic Association Annual Congress in Stockholm and at the Labor Market Frictions and Macroeconomic Dynamics at Université du Québec à Montrèal for useful comments, with special gratitude to Paul Beaudry and Per Krusell. This material is based upon work supported by the National Science Foundation under grant number 0079345 and by the Alfred P. Sloan Foundation. The views expressed herein are those of the authors and not necessarily those of the National Bureau of Economic Research.

(C2004 by Robert Shimer. All rights reserved. Short sections of text, not to exceed two paragraphs, may be quoted without explicit permission provided that full credit, including (C) notice, is given to the source. 
The Consequences of Rigid Wages in Search Models

Robert Shimer

NBER Working Paper No. 10326

February 2004

JEL No. E24, E32, J30, J41, J63, J64

\title{
$\underline{\text { ABSTRACT }}$
}

The standard theory of equilibrium unemployment, the Mortensen-Pissarides search and matching model, cannot explain the magnitude of the business cycle fluctuations in two of its central elements, unemployment and vacancies. Modifying the model to make the present value of wages unresponsive to current labor market conditions amplifies fluctuations in unemployment and vacancies by an order of magnitude, significantly improving the performance of the model. Despite this, the welfare consequences of such rigid wages is negligible.

\author{
Robert Shimer \\ University of Chicago \\ Department of Economics \\ 1126 East $59^{\text {th }}$ Street \\ Chicago, IL 60637 \\ and NBER \\ shimer@uchicago.edu
}




\section{Introduction}

A sequence of recent papers (Costain and Reiter 2003, Hall 2003a, Shimer 2003) has argued that the standard theory of equilibrium unemployment, the Mortensen-Pissarides search and matching model (Mortensen and Pissarides 1994, Pissarides 2000) cannot explain the magnitude of the cyclical fluctuations in two of its central elements, unemployment and vacancies. Firms create more vacancies in response to an increase in labor productivity. This reduces the duration of unemployment, putting upward pressure on wages. In a reasonably calibrated version of the economy, the wage increase absorbs virtually all of the productivity increase, and so the shock scarcely affects unemployment and vacancies.

Hall (2003b) introduces a real wage rigidity, a backward-looking social norm, into the Mortensen-Pissarides model, and shows that the resulting model quantitatively matches the behavior of unemployment and vacancies in the U.S.. The wage rigidity is socially inefficient: wages are too low in expansions, inducing excessive vacancy creation, and too high in recessions, discouraging most vacancy creation. Nevertheless, Hall (2003b) shows that there are no bilateral gains from renegotiating the wage; every employed worker always prefers to receive a higher wage and every employer always wants to pay a lower wage. The model thereby avoids Barro's (1977) critique that in many implicit contract models, workers and firms do not exploit all the potential gains from trade.

This paper first reviews Shimer's (2003) argument that the Mortensen-Pissarides matching model cannot generate substantial fluctuations in unemployment and vacancies. It then explores the consequences of introducing rigid wages. Although the model's behavior does not depend on the extent of wage flexibility in existing employment relationships, it is dramatically altered if the wage for new hires is independent of the current state of aggregate productivity. In the latter case, the model easily generates large fluctuations in unemployment and vacancies. Finally, the paper asks a variant of Lucas's (1987) cost-of-business-cycle question. Suppose real wages are constant. How much would a worker be willing to pay to eliminate the real wage rigidity, so wages instead vary optimally over the business cycle? In a calibrated example, the cost of the real wage rigidity is small, about 0.1 percent of lifetime consumption, even though the rigidity amplifies fluctuations in unemployment and vacancies by more than a factor of ten. To the extent that policies designed to make real wages more flexible ${ }^{1}$ are difficult to implement, unevenly effective, and have unintended consequences, this

\footnotetext{
${ }^{1}$ Monetary policy may have such an effect if nominal wages are sticky.
} 
analysis suggests that they are unlikely to be desirable even in an economy in which real wages would otherwise be fixed.

\section{$2 \quad$ Flexible Wage Model}

I start by extending Pissarides (1985) to make labor productivity $p$ stochastic. Because the model has become fairly standard, I describe it only briefly. ${ }^{2}$

Time is continuous. The economy consists of a measure 1 of risk-neutral, ${ }^{3}$ infinitelylived workers and a continuum of risk-neutral, infinitely-lived firms. Workers and firms discount future payoffs at a common rate $r>0$, but I focus on limiting results as $r \rightarrow 0$. Workers can either be unemployed or employed. An unemployed worker gets flow utility $z$ from non-market activity ('leisure') and searches for a job. An employed worker earns an endogenous productivity-contingent wage $w_{p}$ but may not search.

Firms have a constant returns to scale production technology that uses only labor; each worker yields profit equal to the difference between labor productivity and the wage, $p-w_{p}$. Jobs end exogenously at rate $s>0$, leaving the worker unemployed and the firm with a vacancy. In order to hire a worker, a firm must maintain an open vacancy at flow cost $c$.

There is a Cobb-Douglas, constant returns to scale matching technology, ${ }^{4}$ so that the rate at which unemployed workers find jobs and the rate at which vacancies are filled depends only on the endogenous productivity-contingent vacancy-unemployment ratio $\theta_{p}$. More precisely, workers find jobs at rate $\mu \theta_{p}^{1-\alpha}$ and vacancies are filled at rate $\mu \theta_{p}^{-\alpha}$, where $\alpha \in(0,1)$ is the elasticity of the matching function with respect to the unemployment rate. The unemployment rate $u(t)$ increases with job destruction and decreases when workers find jobs, and so evolves according to

$$
\dot{u}(t)=s(1-u(t))-\mu \theta_{p(t)}^{1-\alpha} u(t)
$$

where $p(t)$ is the level of labor productivity at time $t$.

An aggregate shock hits the economy according to a Poisson process with arrival rate $\lambda$, at which point a new productivity $p^{\prime}$ is drawn from a distribution that depends

\footnotetext{
${ }^{2}$ See Pissarides (2000) for a textbook treatment of the deterministic search model and Shimer (2003) for a discussion of the stochastic model.

${ }^{3}$ Alternatively one can view this as a complete markets model in which labor income risk is insured.

${ }^{4}$ Petrongolo and Pissarides (2001) argue that the matching function exhibits constant returns to scale. There has been less analysis of the Cobb-Douglas assumption, which is central to the interpretation of some of the results that follow. See Blanchard and Diamond (1989) for an estimate of a CES matching function; they cannnot reject a unit elasticity of substitution, the Cobb-Douglas case.
} 
on the current productivity level $p$. Let $\mathbb{E}_{p} X_{p^{\prime}}$ denote the expected value of an arbitrary variable $X$ following the next aggregate shock, conditional on the current state $p$. Also assume that the support of the unconditional productivity distribution is compact so this conditional expectation is well-defined. Current productivity and the stochastic process for productivity are common knowledge.

The verbal description above is precisely summarized by four Bellman equations:

$$
\begin{aligned}
& r U_{p}=z+\mu \theta_{p}^{1-\alpha}\left(E_{p}-U_{p}\right)+\lambda\left(\mathbb{E}_{p} U_{p^{\prime}}-U_{p}\right) \\
& r E_{p}=w_{p}+s\left(U_{p}-E_{p}\right)+\lambda\left(\mathbb{E}_{p} E_{p^{\prime}}-E_{p}\right) \\
& r V_{p}=-c+\mu \theta_{p}^{-\alpha}\left(F_{p}-V_{p}\right)+\lambda\left(\mathbb{E}_{p} V_{p^{\prime}}-V_{p}\right) \\
& r F_{p}=p-w_{p}+s\left(V_{p}-F_{p}\right)+\lambda\left(\mathbb{E}_{p} F_{p^{\prime}}-F_{p}\right)
\end{aligned}
$$

The first pair of equations describe the value of a worker when she is unemployed $(U)$ and employed $(E)$ as a function of the current productivity level $p .^{5}$ If she is unemployed, she gets current value from leisure $z$ and finds a job at rate $\mu \theta_{p}^{1-\alpha}$. There is also an aggregate shock at rate $\lambda$, giving a capital gain $\mathbb{E}_{p} U_{p^{\prime}}-U_{p}$. When she is employed, she earns the endogenous wage $w_{p}$, loses her job at rate $s$, and realizes an aggregate shock at rate $\lambda$. The second pair of equations similarly describe the value of a job that is vacant $(V)$ or filled $(F)$.

For each productivity level $p$, there are six endogenous variables within the four equations (2)-(5): four Bellman values, the vacancy-unemployment ratio $\theta_{p}$, and the wage $w_{p}$. To close the model, we need two additional equations. One is a free entry condition for vacancies: firms create job openings until the value of a vacancy is zero,

$$
V_{p}=0 \text { for all } p
$$

The other assumption, dating back at least to Pissarides (1985), is that wages are set by asymmetric Nash bargaining. I assume here that wages are renegotiated following each aggregate shock, which ensures that at any point in time all workers are paid a common wage $w_{p}$. Section 4 considers an extreme alternative, in which the wage in existing jobs is fixed following an aggregate shock. In the present context, the Nash bargaining assumption amounts to

$$
\frac{E_{p}-U_{p}}{\beta}=\frac{F_{p}-V_{p}}{1-\beta} \text { for all } p,
$$

\footnotetext{
${ }^{5}$ These equations implicitly assume that the value functions are independent of the unemployment rate. It is straightforward to show that there is an equilibrium with such a property. In fact, there is no equilibrium in which the value functions depend on the unemployment rate or on any 'sunspot' variable.
} 
where $\beta \in(0,1)$ represents workers' bargaining power.

Since the six equations (2)-(7) are linear in five of the endogenous variables, $U_{p}, E_{p}$, $V_{p}, F_{p}$, and $w_{p}$, we can eliminate these variables algebraically to get a forward-looking non-linear difference equation for the vacancy-unemployment ratio:

$$
\frac{r+s+\lambda}{\mu \theta_{p}^{-\alpha}}+\beta \theta_{p}=(1-\beta) \frac{p-z}{c}+\lambda \mathbb{E}_{p} \frac{1}{\mu \theta_{p^{\prime}}^{-\alpha}} .
$$

It is also possible to express the wage as a function of the contemporaneous vacancyunemployment ratio and model parameters:

$$
w_{p}=\beta\left(p+c \theta_{p}\right)+(1-\beta) z
$$

Equations (8) and (9) are easily solved numerically for arbitrary parameter values, while the unemployment rate is determined from equation (1).

\section{Calibration}

Table 1 shows summary statistics for productivity, wages, unemployment, and vacancies using quarterly data from the U.S. from 1951 to $2001 .^{6}$ Productivity and wages are constructed by the Bureau of Labor Statistics (BLS) from the National Income and Product Accounts and the Current Employment Statistics. The former is measured as real output per hour in the non-farm business sector; the latter is real hourly compensation in the same sector. It is a broad measure of compensation, including wages, salaries, tips, bonuses, and in-kind payments, as well as imputed compensation for proprietors and unpaid family workers. Unemployment is measured by the BLS using the Current Population Survey. Vacancies are crudely measured by the Conference Board help-wanted advertising index, but this variable closely tracks direct measures of vacancies when they are available (Abraham 1987, Shimer 2003). All data are detrended using a very low frequency Hodrick-Prescott filter with smoothing parameter 100,000, so the detrended data include both short- and medium-frequency fluctuations.

Following Shimer (2003), I calibrate the model to match this data. The parameter choices are summarized in Table 2 . Here I mention two that are particularly important for the interpretation of the results. First, I set the discount rate to zero. Compared with a more standard number, say 0.01 per quarter, this choice scarcely affects the

\footnotetext{
${ }^{6}$ The U.S. economy is an interesting benchmark because, relative to most European economies, it is thought to have flexible wages. The finding that wages in the U.S. economy are significantly more rigid than in the benchmark model is therefore all-the-more surprising.
} 
quantitative results; however, it simplifies the normative analysis because welfare only depends on the long-run behavior of the economy and in particular is independent of the current state. Second, I set workers' bargaining power $\beta$ equal to the elasticity of the matching function $\alpha$. Shimer (2003) proves that if $\beta=\alpha$, the equilibrium in the economy with Nash bargaining maximizes the expected present value of output net of vacancy costs, even in the presence of productivity shocks, a generalization of the Hosios (1990) condition. Again, this restriction facilitates the normative analysis.

Table 3 summarizes the model generated data. Although it is a continuous time model, I sample the model-generated data at discrete points in time corresponding to the end of each quarter so as to make it comparable with actual data. I chose parameters to match the mean unemployment rate and the standard deviation and first-order autocorrelation of labor productivity. The model-generated data can be compared with U.S. data along the remaining dimensions. In some cases, the model performs very well. For example, the correlation between unemployment and vacancies in this data set is -0.90 , while in the model it is -0.87 , so the model can produce a downward sloping 'Beveridge curve' or vacancy-unemployment relationship. On others, the model performs less well. In the data, vacancies are slightly more persistent than unemployment, while in the model vacancies are much less persistent. Introducing planning lags would presumably correct this shortcoming (Fujita 2003). But the real problem lies in the absence of volatility. The unemployment rate is 15.2 times as volatile in the data as in the model, the vacancy rate is 11.4 times, and the vacancyunemployment ratio is 12.5 times. The Mortensen-Pissarides model generates only a tiny fraction of the volatility of its two central elements, unemployment and vacancies.

\section{Rigid Wages in Old Matches}

This section observes that the rigidity of wages in old matches does not affect the volatility of unemployment and vacancies. Consider an extreme alternative to the previous section's assumptions: the wage in new matches is determined by Nash bargaining, but it never changes following subsequent shocks. Let $w^{p_{0}}$ denote the wage in a match that was formed when productivity was equal to $p_{0}$. The model is otherwise 
unchanged. We may express the Bellman equations as

$$
\begin{aligned}
r U_{p} & =z+\mu \theta_{p}^{1-\alpha}\left(E_{p}^{p}-U_{p}\right)+\lambda\left(\mathbb{E}_{p} U_{p^{\prime}}-U_{p}\right) \\
r E_{p}^{p_{0}} & =w^{p_{0}}+s\left(U_{p}-E_{p}^{p_{0}}\right)+\lambda\left(\mathbb{E}_{p} E_{p^{\prime}}^{p_{0}}-E_{p}^{p_{0}}\right) \\
r V_{p} & =-c+\mu \theta_{p}^{-\alpha}\left(F_{p}^{p}-V_{p}\right)+\lambda\left(\mathbb{E}_{p} V_{p^{\prime}}-V_{p}\right) \\
r F_{p}^{p_{0}} & =p-w^{p_{0}}+s\left(V_{p}-F_{p}^{p_{0}}\right)+\lambda\left(\mathbb{E}_{p} F_{p^{\prime}}^{p_{0}}-F_{p}^{p_{0}}\right),
\end{aligned}
$$

where superscripts denote initial productivity and subscripts denote current productivity. The free entry condition (6) is unchanged, while the Nash bargaining solution need only obtain in new matches:

$$
\frac{E_{p}^{p}-U_{p}}{\beta}=\frac{F_{p}^{p}-V_{p}}{1-\beta} \text { for all } p
$$

It is straightforward to prove that the state-contingent vacancy-unemployment ratio, given in equation (8), is unaffected by this modification of the model, since match surplus $S_{p} \equiv F_{p}^{p_{0}}+E_{p}^{p_{0}}-U_{p}$ is independent of the initial productivity level. It follows that the response of unemployment and vacancies to a labor productivity shock is the same in this model as in the flexible wage model.

The wage equation, however, is altered by this modification:

$$
w^{p}=\beta\left(p+c \theta_{p}\right)+(1-\beta) z+\frac{\lambda}{r+s} \mathbb{E}_{p}\left(w^{p^{\prime}}-w^{p}\right) .
$$

Although the expected present value of wages as a function of initial productivity is the same if wages are continually renegotiated and hence depend only on current productivity (equation 9) or if they are fixed for the duration of the match and hence depend only on initial productivity (equation 15), the timing of wage payments is quite different. The coefficient of variation on the cross-sectional average wage declines from 0.016 to 0.004 , the first order autocorrelation jumps up from 0.85 to 0.99 , and the correlation between the average wage and labor productivity drops from 1.00 to 0.62 . This exercise indicates that the volatility of wages are not informative about the success of a model with long term employment relationships, echoing the conclusion reached by Boldrin and Horvath (1995). 


\section{Rigid Wages in All Matches}

Following the analysis in Hall (2003b), this section demonstrates the improved performance of the model if the expected present value of wages in new matches is rigid. I make an extreme assumption here and replace the Nash bargaining solution (7) with a fixed wage, $w^{p}=\bar{w}^{7}$ It is simplest to view this as a social norm. All workers expect to be paid $\bar{w}$ when employed, and all firms expect to have to pay $\bar{w}$ to any employee. Crucially, a matched worker and firm have no incentive to renegotiate the wage. An employed worker always prefers a higher wage, so long as this does not induce the firm to lay her off (i.e. as long as $F_{p}>0$ ), and an employer always prefers to pay a lower wage, so long as this does not induce the worker to quit (i.e. as long as $E_{p}>U_{p}$ ). I focus throughout on a range of parameter values for which these conditions hold. An equilibrium is a solution to equations (2)-(6), with a constant and exogenous wage. The vacancy-unemployment ratio satisfies a forward-looking differential equation,

$$
\frac{r+s+\lambda}{\mu \theta_{p}^{-\alpha}}=\frac{p-\bar{w}}{c}+\lambda \mathbb{E}_{p} \frac{1}{\mu \theta_{p^{\prime}}^{-\alpha}}
$$

with $\theta_{p}$ truncated at zero.

I fix all the parameters (except workers' bargaining power $\beta$ ) at their values in Table 2 and then characterize the equilibrium with the wage fixed at $\bar{w}=0.967$, chosen to replicate the appropriate average unemployment rate, 5.7 percent. Table 4 records the results. The autocorrelations and correlation matrix are almost unchanged. For example, the correlation between unemployment and vacancies becomes slightly less negative, -0.85 rather than -0.87 , while the lack of persistence in vacancies remains a problem. But the variability of unemployment and vacancies rises dramatically. Unemployment is almost exactly as variable in the model as in the U.S. data, while vacancies are somewhat more variable in the model than in the data. The naïve assumption that wages are constant significantly improves the performance of the model. ${ }^{8}$

\footnotetext{
${ }^{7} \mathrm{~A}$ shortcoming of this assumption is that long-run productivity growth will counterfactually induce a long-run decline in the unemployment rate. Hall (2003b) makes a more complicated assumption on wage setting that ensures a similar behavior of the model in the short-run but a more satisfactory response to long-run trends.

${ }^{8} \mathrm{I}$ have also calibrated the model allowing productivity and wages to follow the joint stochastic process observed in U.S. data. This enriches the model by adding a 'wage shock'; however, since the vacancyunemployment ratio is determined by the (current and expected future) difference between productivity and wages - see equation (16) - it is possible to reduce the driving force to a single variable, net profit $p-w$. I set the mean value of net profit at 0.032 , as in the flexible wage model. U.S. data then imply that the coefficient of variation and first order autocorrelation of net profit are 0.522 and 0.858 , respectively. In response to these productivity and wage shocks, the calibrated model delivers fluctuations in unemployment
} 


\section{The Welfare Cost of Rigid Wages}

If rigid wages have a large effect on the equilibrium unemployment and vacancy rates, it seems natural that they would also have a large effect on welfare. During good times, wages are too low and so the vacancy-unemployment ratio $\theta$ is too high, while in bad times the opposite is true. This section asks how much consumption a worker would sacrifice in order to live in a world with flexible wages in new matches (Sections 2-4) rather than a world with rigid wages (Section 5). In the calibrated rigid wage economy, average output is 0.12 percent below the level in the flexible wage economies, and so workers would give up 0.12 percent of their average consumption to move to a flexible wage economy, a negligible amount. ${ }^{9}$ While a fixed real wage dramatically alters the behavior of unemployment and vacancies, it scarcely affects welfare.

There are at least two important caveats to this result. First, since workers are riskneutral, this calculation is based on the cost that rigid wages impose on the mean level of consumption. The variance in consumption also matters if workers are risk-averse and capital markets are incomplete; however, calculations by Lucas (1987) and others indicate that the cost of consumption variability is small even in non-representative agent economies (Imrohoroglu 1989, Atkeson and Phelan 1994, Obstfeld 1994) or in economies with non-standard preferences (Alvarez and Jermann 2000).

Second, if the wage level is fixed at a different level, $\bar{w} \neq 0.967$, the welfare costs may be much more significant. But this is not really a statement about wage rigidity in the presence of productivity fluctuations; it is similarly true that if wages are flexible but workers' bargaining power $\beta$ is not equal to the elasticity $\alpha$, welfare may be reduced substantially. I leave for future research the question of why a rigid real wage might or might not tend towards the efficient level in the long-run. ${ }^{10}$

and vacancies similar to those in the fixed wage model: a coefficient of variation for unemployment of 0.183 and for vacancies of 0.242 , with a correlation between these two key variables equal to -0.861 .

${ }^{9} \mathrm{I}$ have rigged the model so that this question is conceptually easy to answer. First, since the discount rate is 0 , the cost of rigid wages depends neither on the current state of the economy nor on the dynamics of moving to a new ergodic employment and wage distribution. Second, in a flexible wage economy, workers' bargaining power $\beta$ equals the elasticity of the matching function $\alpha$, so the comparison is between a rigid wage economy and an economy with wages that move optimally over the business cycle (Hosios 1990). And third, since workers are risk-neutral, the proper measure of welfare is simply workers' average consumption, which is equal to the average output in the economy net of vacancy posting costs. When productivity is $p$, the unemployment rate is $u$, and the vacancy-unemployment ratio is $\theta$, net output is $(1-u) p+u z-c \theta u$, the sum of income from the $1-u$ employed workers and from the $u$ unemployed workers minus the cost of the $v=\theta u$ vacancies.

${ }^{10}$ One way to sidestep this issue is to ask how much consumption a worker would sacrifice in order to eliminate productivity fluctuations, analogous with Lucas (1987). One can compare this sacrifice in economies with flexible and rigid wages. Such a calculation is likely to be less sensitive to the choice of the level of wages and bargaining power. I thank Paul Beaudry for this suggestion. 


\section{Conclusion}

I have extended the Mortensen-Pissarides search and matching model with the simplest possible model of rigid wages, a constant wage. With wages determined by Nash bargaining, unemployment and vacancies are much less variable in the model than in the U.S. economy. A constant wage generates approximately the correct variance for these two key variables. In other words, this model provides some support, in the context of a modern model of equilibrium unemployment, for the Keynesian notion that real wage rigidities exacerbate cyclical fluctuations, so recessions are times when real wages are too high. At the same time, a fixed real wage need not have any significant welfare cost. This suggests that, to the extent government policies distort the economy along other dimensions, policies designed to make real wages more flexible are likely to be counterproductive, even if they succeed in moderating employment and vacancy fluctuations.

\section{References}

Abowd, John, And Arnold Zellner (1985): "Estimating Gross Labor-Force Flows," Journal of Business and Economic Statistics, 3(3), 254-283.

Abraham, Katharine (1987): "Help-Wanted Advertising, Job Vacancies, and Unemployment," Brookings Papers on Economic Activity, 1, 207-243.

Alvarez, Fernando, and Urban Jermann (2000): "Using Asset Prices to Measure the Cost of Business Cycles," NBER Working Paper 7978.

Atkeson, Andrew, And Christopher Phelan (1994): "Reconsidering the Costs of Business Cycles with Incomplete Markets," in NBER Macroeconomics Annual, ed. by Stanley Fischer, and Julio Rotemberg, vol. 9, pp. 187-207. MIT Press, Cambridge.

Barro, Robert (1977): "Long-Term Contracting, Sticky Prices, and Monetary Policy," Journal of Monetary Economics, 3(3), 305-316.

Blanchard, Olivier, and Peter Diamond (1989): "The Beveridge Curve," Brookings Papers on Economic Activity, 1, 1-60.

Boldrin, Michele, And Michael Horvath (1995): "Labor Contracts and Business Cycles," Journal of Political Economy, 103(5), 972-1004.

Costain, James, and Michael Reiter (2003): "Business Cycles, Unemployment Insurance, and the Calibration of Matching Models," Universidad Carlos III Mimeo. 
Fujita, Shigeru (2003): "The Beveridge Curve, Job Creation and the Propagation of Shocks," University of California at San Diego Mimeo.

Hall, Robert (2003a): "Modern Theory of Unemployment Fluctuations: Empirics and Policy Applications," American Economic Review Papers and Proceedings, 93(2), 145-150.

(2003b): "Wage Determination and Employment Fluctuations," NBER Working Paper 9967.

Hosios, Arthur (1990): "On the Efficiency of Matching and Related Models of Search and Unemployment," Review of Economic Studies, 57, 279-298.

Imrohoroglu, Ayse (1989): "Cost of Business Cycles iwth Indivisibilities and Liquidity Constraints," Journal of Political Economy, 97(6), 1364-1383.

LucAs, RoBert (1987): Models of Business Cycles. Basil Blackwell, Oxford.

Mortensen, Dale, And Christopher Pissarides (1994): "Job Creation and Job Destruction in the Theory of Unemployment," Review of Economic Studies, 61, $397-415$.

Obstfeld, Maurice (1994): "Evaluating Risky Consumption Paths: The Role of Intertemporal Substitutability," European Economic Review, 38(7), 1471-1486.

Petrongolo, Barbara, and Christopher Pissarides (2001): "Looking into the Black Box: A Survey of the Matching Function," Journal of Economic Literature, 39(2), 390-431.

Pissarides, Christopher (1985): "Short-Run Equlibrium Dynamics of Unemployment, Vacancies, and Real Wages," American Economic Review, 75, 676-690.

(2000): Equilibrium Unemployment Theory. MIT Press, Cambridge, MA, second edn.

Shimer, Robert (2003): "The Cyclical Behavior of Equilibrium Unemployment and Vacancies: Evidence and Theory," NBER Working Paper 9536. 
Table 1: Summary Statistics, quarterly U.S. data, 1951 to 2001

\begin{tabular}{rrrrrrr}
\hline \hline & & & $u$ & $v$ & $\theta$ & $w$ \\
\cline { 2 - 7 } Mean & - & 0.0567 & - & - & - \\
Coefficient of Variation & 0.017 & 0.188 & 0.183 & 0.344 & 0.013 \\
Autocorrelation (1 Quarter) & 0.854 & 0.918 & 0.930 & 0.938 & 0.892 \\
\hline Correlation Matrix & $p$ & $u$ & $v$ & $\theta$ & $w$ \\
$p$ & 1 & -0.367 & 0.362 & 0.359 & 0.376 \\
$u$ & - & 1 & -0.896 & -0.949 & -0.167 \\
$v$ & - & - & 1 & 0.955 & 0.136 \\
$\theta$ & - & - & - & 1 & 0.175 \\
$w$ & - & - & - & - & 1 \\
\hline
\end{tabular}

Notes: Average labor productivity $p$ is real average output per hour in the non-farm business sector, constructed by the Bureau of Labor Statistics (BLS) from the National Income and Product Accounts (NIPA) and the Current Employment Statistics (CES). The unemployment rate $u$ is constructed by the BLS from the Current Population Survey. The help-wanted advertising index $v$ is constructed by the Conference Board. The wage $w$ is real hourly compensation in the non-farm business sector, constructed by the BLS from the NIPA and CES. Both $u$ and $v$ are quarterly averages of seasonally adjusted monthly series. Productivity, unemployment, vacancies, and wages are expressed as ratios to an HP filter with smoothing parameter $10^{5}$. The coefficient of variation is the ratio of the standard deviation to the mean. 
Table 2: Parameter choices

\begin{tabular}{clll}
\hline \hline variable & meaning & value & explanation \\
\hline $\bar{p}$ & labor productivity: mean & 1.000 & Normalization \\
$\sigma$ & labor productivity: inst. std. dev. & 0.016 & Output per hour in the \\
$\gamma$ & labor productivity: mean reversion & 0.16 & non-farm business sector \\
$r$ & discount rate & 0 & Simplify welfare analysis \\
$s$ & separation rate & 0.1 & Abowd and Zellner $(1985)$ \\
$z$ & value of leisure & 0.4 & Benefit replacement ratio $40 \%$ \\
$c$ & vacancy cost & 0.53 & Normalization $\theta \approx 1$ \\
$\mu$ & matching function constant & 1.65 & Unemployment rate $5.7 \%$ \\
$\alpha$ & matching function elasticity & 0.5 & Petrongolo and Pissarides $(2001)$ \\
$\beta$ & worker's bargaining power & 0.5 & Decentralized equilibrium is optimal \\
\hline
\end{tabular}

Notes: Additional details are provided in the text. Labor productivity takes on three possible values, $0.976474,1$, and 1.02449. A shock hits at rate $\lambda=0.16$. If the old productivity level is not equal to 1 , it adjusts there immediately. If it is equal to 1 , it moves with equal probability to 0.976474 or 1.02449 . 
Table 3: Model-Generated Data, Nash-Bargaining

\begin{tabular}{rrrrrr}
\hline \hline & $p$ & $u$ & $v$ & $\theta$ & $w$ \\
\cline { 2 - 7 } Mean & 1.000 & 0.0569 & 0.0575 & 1.011 & 0.968 \\
Coefficient of Variation & 0.017 & 0.012 & 0.016 & 0.027 & 0.016 \\
Autocorrelation (1 Quarter) & 0.852 & 0.920 & 0.719 & 0.852 & 0.852 \\
\hline Correlation Matrix & $p$ & $u$ & $v$ & $\theta$ & $w$ \\
$p$ & 1 & -0.957 & 0.975 & 1.000 & 1.000 \\
$u$ & - & 1 & -0.868 & -0.957 & -0.957 \\
$v$ & - & - & 1 & 0.975 & 0.975 \\
$\theta$ & - & - & - & 1 & 1.000 \\
$w$ & - & - & - & - & 1 \\
\hline
\end{tabular}

Note: Parameterization given in Table 2. 
Table 4: Model-Generated Data, Fixed Wage at $\bar{w}=0.967$

\begin{tabular}{rrrrrr}
\hline \hline & $p$ & $u$ & $v$ & $\theta$ & $w$ \\
\cline { 2 - 7 } Mean & 1.000 & 0.0572 & 0.0595 & 1.112 & 0.967 \\
Coefficient of Variation & 0.017 & 0.185 & 0.228 & 0.381 & 0 \\
Autocorrelation (1 Quarter) & 0.852 & 0.920 & 0.715 & 0.851 & - \\
\hline Correlation Matrix & $p$ & $u$ & $v$ & $\theta$ & $w$ \\
$p$ & 1 & -0.942 & 0.972 & 0.996 & - \\
$u$ & - & 1 & -0.852 & -0.923 & - \\
$v$ & - & - & 1 & 0.967 & - \\
$\theta$ & - & - & - & 1 & - \\
\hline
\end{tabular}

Note: Parameterization given in Table 2. 